\title{
Conteúdos da oralidade: \\ o gênero discursivo seminário na aula de lingua portuguesa
}

Content of orality: the discursive genre seminar in Portuguese language teaching

Cinara Sousa da Silva

Universidade do Estado da Bahia - UEB

Adelino Pereira dos Santos

Universidade do Estado da Bahia - UEB

DOI: https://doi.org/10.5902/2176148536813

Resumo: Este trabalho tem como objetivo apresentar reflexões sobre conteúdos de ensinoaprendizagem de gêneros discursivos orais da instância pública nas aulas de Língua Portuguesa da educação básica, bem como propor quadros de tais conteúdos a partir do recorte/gênero discursivo oral seminário. 0 trabalho de pesquisa aqui apresentado tem caráter bibliográfico, mas faz parte de um projeto de pesquisa-ação de cunho etnográfico desenvolvido e descrito na dissertação de Mestrado Profissional em Letras de um dos autores deste trabalho, defendida no primeiro trimestre de 2019.

Palavras-chave: Oralidade. Gêneros discursivos. Seminário. Ensino de Língua Portuguesa.

\begin{abstract}
This work has as objective to present reflections on teaching-learning contents of oral discursive genres of the public instance in Portuguese Language Teaching, as well as to propose tables of such contents from the oral discursive genre seminar. The research work presented here has a bibliographic character, but it is part of an ethnographic research project developed and described in the Professional Master's Degree thesis in Language Teaching of one of the authors of this work, defended in the first quarter of 2019.
\end{abstract}

Keywords: Orality. Discursive genres. Seminar. Portuguese Language Teaching. 


\section{Introdução}

Este trabalho parte do pressuposto de que são os gêneros discursivos as ferramentas e dispositivos utilizados pelo homem para a comunicação e interação com o outro e, por isso, devem estar no cerne dos estudos sobre a língua, não apenas como suportes para o ensino da língua ma-

Cinara Sousa

da Silva

Adelino

Pereira dos

Santos terna. Sabemos, todavia, que introduzir gêneros discursivos orais como objetos de ensino-aprendizagem e avaliação das habilidades linguísticas dos alunos não tem sido uma prática constante nas salas de aula de Língua Portuguesa, nem de fácil aplicabilidade devido a diversos fatores. Dentre esses empecilhos, talvez os que mais se destaquem sejam a valoração do escrito em detrimento do oral e a não compreensão por parte dos professores sobre os aspectos constitutivos dos gêneros da oralidade. $O$ primeiro fator vem sendo aos poucos combatido em meio à evolução das pesquisas recentes na área da Linguística, sobres as práticas de interação oral; já o segundo perdura em decorrência da dificuldade que temos em identificar regularidades no texto oral, que sejam passíveis ao ensino e à avaliação.

Outro fator que tolhe o uso dos gêneros discursivos orais no processo ensino-aprendizagem da língua está em o profissional da educação não conseguir transpor o saber acadêmico para o saber a ser ensinado. Apesar dos muitos estudos e pesquisas sobre os gêneros discursivos, a partir de diversos pressupostos teóricos, no que se refere à sala de aula ainda é visível as limitações na relação teoria e prática. A transposição didática se caracteriza pelas escolhas dos saberes científicos a serem introduzidos nas escolas e nas salas de aula, fazendo com que esses saberes tornem-se ensináveis. Segundo Costa-Maciel (2014, p. 31), há dois momentos de transposição: o que passa pelo currículo formal e livros didáticos e aquele produzido pelo professor, em sala de aula, ao buscar didatizar os conteúdos. Durante esse processo de transposição didática na prática pedagógica, a autora afirma que

O professor seleciona e recorta os conteúdos visando a desenvolver as competências prescritas na proposta pedagógica; oferta prioridade ou não a determinados aspectos do que foi selecionado; estrategicamente divide o conteúdo para facilitar a compreensão do aluno, em seguida relaciona as suas partes; estabelece o tempo de modo a apresentar o conteúdo através da organização de uma sequência, uma ordenação que favoreça a compreensão, 


\begin{abstract}
e sua forma de apresentação. Está envolto nesse saber a ser ensinado o pressuposto de como o aluno aprende e como o professor ensina, o que configura o seu processo de didatização, ocorrendo a transposição didática interna (COSTA-MACIEL, 2014, p. 32).
\end{abstract}

A didatização, como bem especifica a autora, se refere à organização dos saberes de maneira que sejam compreensíveis para o aluno. Dessa forma, o professor é desafiado a construir estratégias de ensino, partindo dos saberes adquiridos, a fim de promover um trabalho sistemático com os gêneros discursivos, de selecionar os conteúdos compatíveis com a turma/ série; bem como possibilitar que o aluno desenvolva a competência no uso da linguagem oral nas diversas situações de interação social, sobretudo nas instâncias públicas. Portanto, este trabalho tem como

Conteúdos da oralidade objetivo apresentar reflexões sobre conteúdos de ensino-aprendizagem de gêneros discursivos orais da instância pública nas aulas de Língua Portuguesa da educação básica, bem como propor quadros de tais conteúdos a partir do recorte/gênero discursivo oral seminário.

O trabalho de pesquisa aqui apresentado tem caráter bibliográfico, mas faz parte de um projeto de pesquisa-ação de cunho etnográfico desenvolvido e descrito na dissertação de Mestrado Profissional em Letras de um dos autores deste trabalho, defendida no primeiro trimestre de 2019 (SILVA, 2019) onde discutimos com mais pertinência e profundidade as características do gênero discurso seminário escolar, bem como tecemos considerações sobre os dispositivos teóricos que sustentam nosso trabalho de pesquisa-ação e intervenção pedagógica. Esperamos que as reflexões constantes deste trabalho possam de alguma forma subsidiar o professor de Língua Portuguesa na elaboração de projetos pedagógicos para prática da oralidade nas instâncias públicas formais.

A exposição oral ${ }^{1}$ ou seminário se configura como um gênero oral do domínio discursivo instrucional (MARCUSCHI, 2008), cuja intenção é desenvolver e partilhar conhecimentos sobre determinado tema, normalmente resultado de pesquisas ou experiências profissionais, além de possibilitar ao expositor e público discutirem sobre ele. $O$ gênero

1 Nesta pesquisa, a exposição oral refere-se ao gênero discursivo seminário, conforme Schneuwly e Dolz (2011). No entanto, destacamos que para alguns autores os dois termos tratam de gêneros distintos, a exemplo de Melo, Marcuschi e Cavalcante (2012, p. 99). Para uma discussão mais aprofundada sobre gêneros discursivos remetemos o leitor à nossa dissertação de mestrado, elencada nas referências deste trabalho. 
tem como característica a formalidade, por envolver um planejamento prévio e regras bem definidas, e de natureza pública, já que há a participação do público.

A proposição desse gênero como recorte de nossa reflexão, neste artigo, decorre das oportunidades que o professor de Língua Portugue-

Cinara Sousa

da Silva

Adelino

Pereira dos

Santos sa pode oferecer ao aluno, para o desenvolvimento de habilidades que emergem da prática verbal em contextos mais formais de uso da língua, requerendo deste maior preparo e organização, bem como o respeito às regras estabelecidas nessa modalidade de comunicação e interação social.

\section{Didatização de gêneros discursivos da oralidade}

De acordo com Fonseca (2014, p. 63), "enquanto sujeitos de uma ação didatizadora, pode-se entender que o professor é responsável por tornar os objetos selecionados pela esfera pedagógica em objetos do seu fazer, através de ferramentas de sua escolha". A autora evidencia que essa prática "não se trata somente das estratégias lançadas pelo professor no decorrer das aulas, mas também estratégias previstas pelos documentos parametrizadores" (Id. Ibid. ). Dessa forma, nossas escolhas aqui estão fundamentadas nos parâmetros da Base Nacional Comum Curricular (BRASIL, 2017), respeitando suas exigências em relação ao trabalho com os gêneros discursivos orais.

Afirmar que os gêneros discursivos são ferramentas e/ou dispositivos atuando nas situações de uso da língua e mediando essa atividade humana, significa considerar que são objetos culturais, bem como ferramentas didáticas que orientam "a realização da ação linguageira, tanto do ponto de vista dos conteúdos que lhes são próprios e que podem ser ditos por meio dele, quanto do ponto de vista de sua estrutura composicional" (DOLZ; GAGNON, 2015, p. 35,36). Partindo desse pressuposto, é de fundamental importância, ao se propor um estudo eficaz da língua envolvendo os gêneros discursivos orais, definir quais conteúdos lhes são característicos e particulares.

Bakhtin (2003) já afirmara a despeito da riqueza de um repertório de gêneros orais (e escritos) que dispomos para moldar nosso discurso. Essa diversidade é determinada pela situação, posição social e interação entre os participantes da comunicação, por isso, torna-se imprescindível seu conhecimento, como bem destaca o autor: "em termos práticos, nós os empregamos de forma segura e habilidosa, mas 
em termos teóricos podemos desconhecer inteiramente sua existência" (BAKHTIN, 2003, p. 282). Se há formas "elevadas", oficiais desses gêneros, assim como formas familiares, precisamos dominá-los bem para também "empregá-los livremente" (Id, Ibid., p. 284). Portanto, destacamos aqui, mais uma vez, a necessidade de delimitarmos, para o estudo dos gêneros discursivos orais, os conteúdos da oralidade, a fim de contemplar seu ensino.

Como professores, compreendemos as dificuldades que temos em identificar as dimensões do oral e, consequentemente, em construir caminhos didáticos que o insira no processo de estudo da língua, especialmente por a oralidade ter sido entendida durante décadas como o lugar do caos e da desordem, como uso menos normativo e sistemático da língua. Sendo assim, este trabalho se insere no desafio de elencar os Conteúdos da oralidade conteúdos da oralidade, por meio de análise bibliográfica dos conhecimentos produzidos cientificamente por especialistas da área, em que se destacam os elementos possíveis de análise nos estudos dos gêneros e as estratégias metodológicas mais viáveis para compor a sequência didática de seu ensino e aprendizagem. Apesar de que, como bem destaca Baumgärtner (2015, p. 100), em uma pesquisa bibliográfica realizada por seu grupo de estudo, "constatou-se que a literatura da área tem sido mais produtiva no campo da oralidade, de um modo geral, do que no estudo de gêneros orais específicos e de suas relações com o ensino de língua".

Ao delimitarmos os conteúdos da oralidade, torna-se mais fácil apresentar ao aluno as formas específicas quando se realiza uma atividade linguística e fazê-lo refletir sobre os elementos que mobilizamos em tal prática. Essa é a maneira de nós, professores, fortalecermos a ideia de que o ensino do oral se concretiza no ensino dos diversos gêneros orais. Em se tratando dos orais formais, há a exigência de uma ação pedagógica planejada, já que se pretende desenvolver a competência linguística do aluno em contextos formais e públicos, que estão para além de seu uso em contextos familiares.

Como uma forma de facilitar a compreensão e formalização das dimensões ensináveis dos gêneros discursivos, teóricos do grupo de estudo de Genebra elaboraram um modelo didático, que descreve as principais características de um gênero, com vistas a seu ensino, também baseado em critérios de validação desse objeto para o ensino: 
critério de legitimidade, que pressupõe os recursos e os saberes válidos, ou por seu estatuto acadêmico, ou por serem considerados como legítimos pelos especialistas da área; critério de pertinência, que avalia a adequação dos recursos e saberes escolhidos em função das finalidades e objetivos escolares; critério de so-

Cinara Sousa

da Silva

Adelino

Pereira dos

Santos

lidarização, que assegura a coerência do conjunto dos recursos mobilizados" ( DOLZ; GAGNON, 2015, p. 41, grifo nosso).

Longe de ser uma fórmula estática, o modelo didático objetiva delinear os aspectos do gênero a serem ensinados na sala de aula, o que facilita também o uso dos gêneros discursivos orais como objeto de ensino-aprendizagem, já que, assim como os escritos, possuem características organizacionais que requer um trabalho sistemático e planejado nas aulas de língua materna. As dimensões do gênero estão resumidas no esquema a seguir:

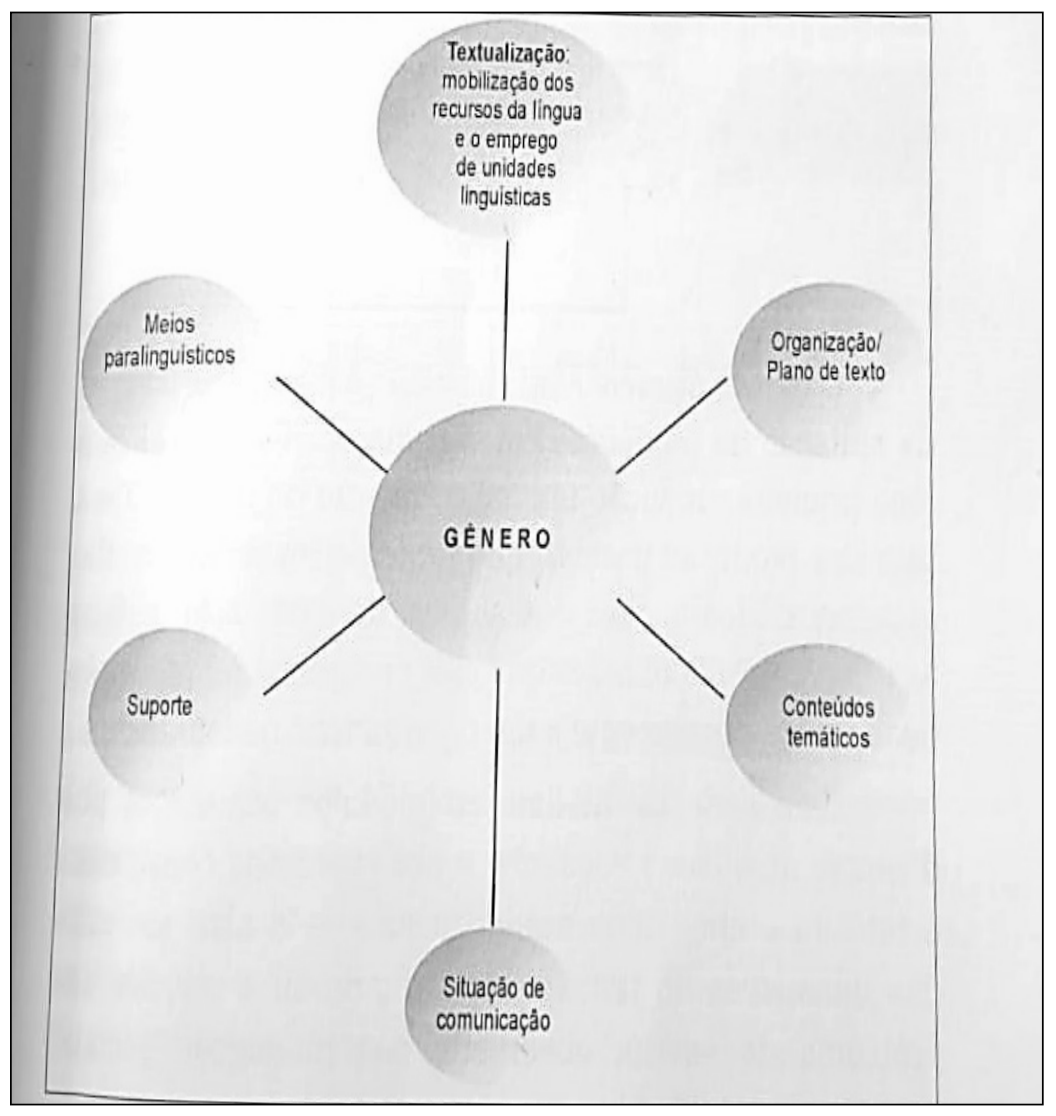

Figura 1 - Modelo didático do gênero FONTE: DOLZ; GAGNON (2015, p. 41). 
Em concordância com a teoria bakhtiniana, o modelo acima compreende o gênero em seus aspectos composicionais, textuais, situacionais e discursivos ao afirmar que o conteúdo temático, o estilo e a construção composicional são elementos constituintes do enunciado (BAKHTIN, 2003, p. 262). Fonseca (2014, p. 28) defende, inclusive, que "não existe gênero sem os elementos constitutivos que o cercam". Dessa maneira, por serem práticas sociais de linguagem, a produção de um gênero discursivo envolve a organização dos enunciados segundo parâmetros linguísticos e extralinguísticos como a esfera comunicativa, a finalidade da interação, a intenção discursiva do falante, os lugares sociais dos interlocutores, bem como seu estilo, além de vários aspectos que influenciam a escolha de um gênero específico e, automaticamente, das unidades linguísticas.

Conteúdos da oralidade

Como bem adverte Dolz e Schneuwly (2011, p. 126) “é necessário definir claramente as características do oral a ser ensinado". Sendo assim, para um trabalho coerente com os gêneros discursivos orais na sala de aula, é preciso que o professor tenha ciência dessas particularidades, observadas no modelo didático (Figura 1), e organize-as de maneira que também possam fazer parte dos estudos linguísticos. É importante destacar que, conforme afirmam Cavalcante e Melo (2007, p. 96), por serem muitos os aspectos para se observar nos gêneros orais públicos, não há a necessidade de o professor se sentir na obrigação de explorar todos eles na sala de aula, mas pode privilegiar um ou outro aspecto marcante para caracterizá-los. As autoras ainda enfatizam a diversidade dos gêneros orais como ponto central no trabalho com a oralidade, que conduza o aluno a refletir sobre a finalidade de cada um, considerando suas características extralinguísticas, paralinguísticas e linguísticas.

Para facilitar o trabalho com a oralidade no contexto escolar, as autoras elaboraram quadros contendo esses aspectos constitutivos dos gêneros orais, com seus respectivos conteúdos. Os quais estão elencados no quadro 1, a seguir: 


\section{Quadro 1 - Aspectos a serem observados na língua}

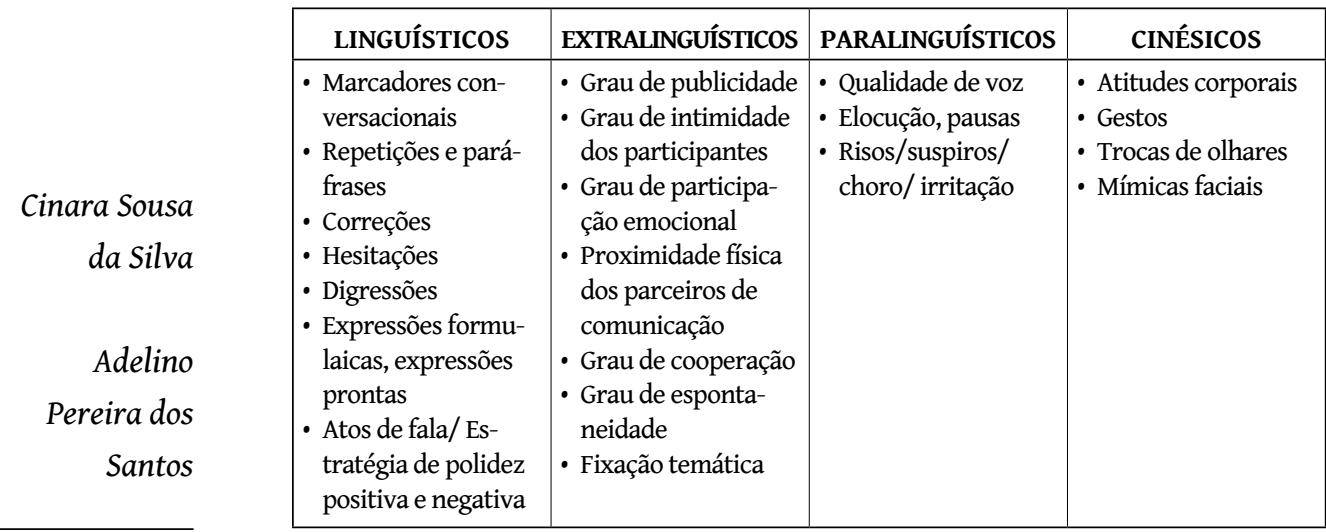

FONTE: CAVALCANTE; MELO (2007, p. 93-96).

Já Dolz e Schneuwly (2011, p. 134), além dos aspectos paralinguísticos e cinésicos, acrescentam outros aspectos, também não-linguísticos, que compõem a comunicação oral: a posição dos locutores, também elencados pelas autoras supracitadas na seção dos extralinguísticos; o aspecto exterior (roupas, disfarces, penteados, óculos, limpeza) e a disposição dos lugares (lugares, disposição, iluminação, disposição das cadeiras, ordem, ventilação, decoração).

Didatizando esses aspectos da comunicação oral, é possível depreender os conteúdos da oralidade, que podem fazer parte de um programa de ensino para o estudo da Língua Portuguesa na educação básica, específico para cada série. Por conteúdo, consideramos aqui todos os elementos que são mobilizados pelo produtor do texto nas diversas práticas de uso da língua. Esses elementos podem derivar do contexto ou da situação de comunicação, das relações entre a língua e o social, do próprio sistema linguístico ou característico do estilo e gênero mobilizados, contanto que se detecte qualquer relação, influência ou condição para que se estabeleça a comunicação e interação pretendidas. Dentre os conteúdos da oralidade podemos citar ${ }^{2}$ :

2 Conteúdos presentes em alguns currículos nacionais. Ver Baumgärtner (2012, p. 64-70). 


\section{Quadro 2 - Relação de alguns conteúdos da oralidade}

\begin{tabular}{|l|l|}
\hline \multicolumn{2}{|c|}{ CONTEÚDOS DA ORALIDADE } \\
\hline - Conteúdo temático; & - Marcas linguísticas (repetição, gírias, \\
- Sequência na exposição de ideias; & - Adequação...); \\
- Argumentação e defesa; & tivos, gírias, repetições...); \\
- Narração de fatos; & - Turnos de fala; \\
- Descrição de situações, objetos, seres & - Variações linguísticas; \\
humanos; & - Coesão e coerência; \\
- Dissertação (confrontação de ideias); & - Diferenças entre o discurso oral e escrito; \\
- Finalidade; & - Articulação, adequação e ampliação de \\
- Aceitabilidade; & palavras; \\
- Informatividade; & - Objetividade e subjetividade; \\
- Intencionalidade discursiva; & - Concordância verbal e nominal; \\
- Papel do locutor e interlocutor; & - Regência verbal e nominal; \\
- Linguagem corporal: expressões faciais, \\
gestual e corporal, pausas, hesitação...; & - Compreensão, interpretação e análise da \\
- Entonação; & fala do outro (interação e sentidos). \\
- Adequação do discurso ao gênero. & \\
\hline
\end{tabular}

Conteúdos da oralidade

FONTE: Quadro elaborado pela pesquisadora, com base em BAUMGÄRTNER (2012, p. 64-70).

A relação de conteúdos dos quadros 2, acima, e 3, a seguir, é apenas ilustrativa, pois muitos outros conteúdos envolvendo o ensino da língua materna podem ser explorados nas análises linguísticas por meio dos gêneros discursivos orais. Ressaltamos que esses conteúdos não estão identificados dentro de uma corrente teórica específica, mas há neles uma tentativa de abarcar os três elementos do enunciado segundo Bakhtin (2003): composição, estilo e conteúdo. Sobre os conteúdos da oralidade, é importante compreender que são elementos característicos da língua oral e, por isso, perpassam, se não todos, a maioria dos gêneros orais. Por isso, cabe ao professor atentar para o que é específico de cada gênero e o que se altera na mudança de gênero. Em outras palavras, temos que realizar as escolhas dos elementos ensináveis a partir do gênero a ser praticado pelos alunos. Quanto àqueles que forem característicos da fala em si, identificar as variações decorrentes do gênero.

Por isso, diante da diversidade de gêneros discursivos orais nas práticas de comunicação, especificamos o seminário para ser o cerne de atividades em sala de aula, conforme vimos teorizando neste trabalho. Tal gênero, além de um instrumento para o desenvolvimento e partilha de conhecimentos, se trabalhado pedagogicamente, serve também para que o aluno perceba que sua construção se dá de maneira coerente e seguindo regularidades. Outro elemento motivador é a característica 
formal desse gênero discursivo oral, que exigirá do aluno sair de sua zona de conforto e expandir a produção do oral que ultrapasse as situações cotidianas e se concretize em situações públicas.

Em consonância com as ideias de Dolz e Schneuwly (2011, p. 147), reconhecemos que "os gêneros formais públicos constituem as

Cinara Sousa

da Silva

Adelino

Pereira dos

Santos

66 formas de linguagem que apresentam restrições impostas do exterior e implicam, paradoxalmente, um controle mais consciente e voluntário do próprio comportamento para dominá-las". Tais propostas poderão possibilitar que o aluno da educação básica supere os entraves para a realização dessas práticas e possam ver o oral formal como uma possibilidade em seu contexto sociocomunicativo.

Compreende-se, dessa forma, a importância da escolha desse gênero da tipologia do expor, já que pretendemos intervir didaticamente nas práticas de uso da língua, prioritariamente, em contextos formais, com foco no desenvolvimento linguístico do aluno. A tipologia do expor é uma sequência linguística importante para desenvolver uma série de habilidades no aluno, tais como um melhor domínio da oralidade; a capacidade de selecionar informações a fim de compor a exposição oral; o uso de estratégias de organização coerente do discurso visando a comunicação e interação entre os interlocutores; possibilidade de ampliação de práticas de linguagem, por meio de atividades de fala, escuta e reflexão; dentre outras. Apresentaremos, na seção a seguir, os conteúdos do gênero discursivo oral seminário.

\section{Conteúdos do gênero discursivo oral seminário: o que ensinar?}

Ao propor trabalhar o seminário na sala de aula, é preciso, inicialmente, conhecer sua dinâmica de funcionamento e regularidades, para finalmente construir estratégias metodológicas que viabilizem a ação do professor. Respeitando as especificações que envolvem o seminário, apresentaremos, a seguir, uma seleção dos conteúdos desse gênero discursivo oral, identificados nas revisões bibliográficas da BNCC (BRASIL, 2017), Leal e Gois (2012), Dolz e Schneuwly (2011), e elencados no quadro abaixo: 


\section{Quadro 3 - Relação de conteúdos do seminário}

\begin{tabular}{|c|c|c|}
\hline $\begin{array}{l}\text { Fenômenos } \\
\text { linguísticos }\end{array}$ & $\begin{array}{c}\text { Fenômenos } \\
\text { paralinguísticos e cinésicos }\end{array}$ & $\begin{array}{c}\text { Estratégias de } \\
\text { organização do discurso }\end{array}$ \\
\hline 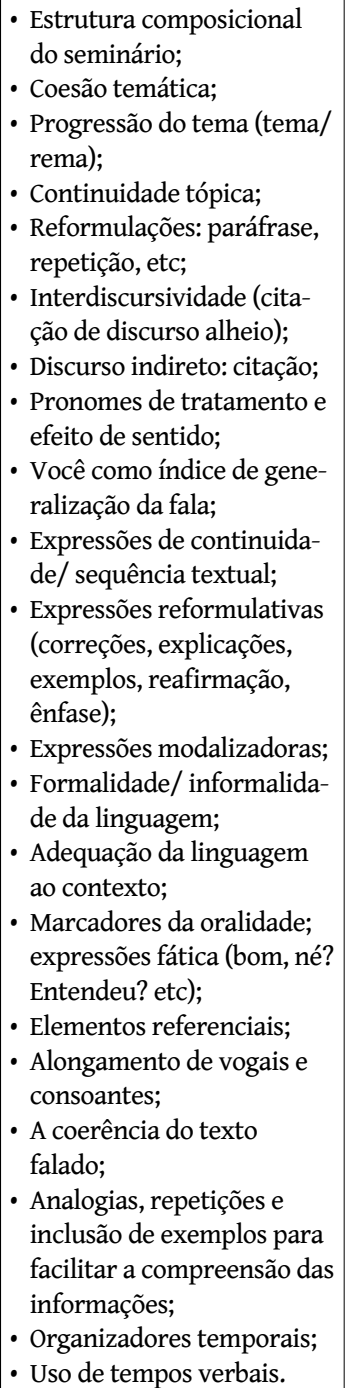 & $\begin{array}{l}\text { - Inflexões; qualidade da } \\
\text { voz, entonação, ritmo, } \\
\text { risos, suspiros, respiração; } \\
\text { - Oralização do texto escrito; } \\
\text { - A organização da gestu- } \\
\text { alidade, das expressões } \\
\text { fisionômicas; mímicas; } \\
\text { - A linguagem corporal; } \\
\text { - Suporte visual; } \\
\text { - Interação; } \\
\text { - Níveis de interação oral; } \\
\text { - Distância e posição dos } \\
\text { locutores; } \\
\text { - Contexto de produção; } \\
\text { - Papéis dos participantes; } \\
\text { - Tempo e espaço. }\end{array}$ & $\begin{array}{l}\text { - Organização interna da } \\
\text { exposição; } \\
\text { - Uso adequado do tempo; } \\
\text { - Exposição didática e objeti- } \\
\text { va da fala; } \\
\text { - Técnicas para conquistar o } \\
\text { público; } \\
\text { - Intencionalidade discur- } \\
\text { siva; } \\
\text { - Antecipação e ênfase; } \\
\text { - Apresentação de dados; } \\
\text { - Uso de recursos audiovi- } \\
\text { suais; } \\
\text { - Escutar com atenção, res- } \\
\text { peito a vez do outro; } \\
\text { - Uso de expressões para } \\
\text { alternância dos turnos } \\
\text { de fala; } \\
\text { - Estratégias para se aproxi- } \\
\text { mar dos ouvintes. }\end{array}$ \\
\hline
\end{tabular}

Conteúdos da oralidade

67

FONTE: Quadro produzido pela pesquisadora a partir de pesquisas bibliográficas - BNCC

(BRASIL, 2017), LEAL e GOIS (2012), DOLZ e SCHNEUWLY e (2011).

No quadro 3, acima, os conteúdos estão separados e identificados como fenômenos linguísticos, quando se tratar de estudos dos aspectos de estruturação das unidades da língua; fenômenos paralinguísticos, cinésicos e extralinguísticos, quando envolver elementos fora do sistema linguísti- 


\section{Cinara Sousa}

da Silva

Adelino

Pereira dos

Santos

68

co, mas de igual importância na execução do gênero e pelas estratégias de organização do discurso, relacionados aos aspectos que utilizamos na construção e organização do texto/discurso durante as práticas comunicativas, podendo estar mais relacionado ao linguístico ou ao extralinguístico.

Em relação às estratégias da organização do discurso, a organização interna da exposição oral constitui uma das dimensões ensináveis do gênero e está ordenada nas seguintes partes: fase de abertura, fase de introdução ao tema, apresentação do plano de exposição, desenvolvimento e encadeamento do tema, recapitulação e síntese, conclusão e encerramento. Essa organização está relacionada ao planejamento do falante para a produção do texto oral, de forma que seja produzido seguindo certas regras de hierarquização. Para Dolz et al (2011), “a exposição deverá ser ordenada em partes e subpartes, que permitam distinguir as fases sucessivas de sua construção interna" (DOLZ et al, 2011, p. 187).

É importante esclarecer que, para os autores supracitados, a organização interna do seminário se refere a um esquema ou suporte para a prática da exposição. Enfatizamos que mesmo não sendo uma característica específica do gênero seminário escolar, essa forma de organização do discurso é essencial para sua execução e, portanto, precisa compor a relação dos seus conteúdos. Como bem enfatizam os autores:

Longe de ser apenas um suporte auxiliar organizado pelo expositor, ele faz parte do modelo didático do gênero e deve ser objeto de uma construção refletida, apoiada na observação das práticas sociais de referência e nos conhecimentos práticos dos alunos (DOLZ et al, 2011, p.190).

A execução dessas etapas contribui para organizar a sequência enunciativa do falante e orientá-lo em como proceder diante do público. Com as três primeiras etapas, por exemplo, é possível construir um vínculo entre os interlocutores, a fim de atrair a atenção e interesse dos ouvintes pelo tema. o desenvolvimento e encadeamento do tema é crucial para que o expositor organize suas ideias, além de favorecer a progressão temática; já a fase de recapitulação e síntese reforça o que fora dito e sinaliza a conclusão do seminário. Esta, por sua vez, assim como o encerramento, são fundamentais para sensibilizar os ouvintes em relação ao exposto, além de possibilitar uma maior interação entre os envolvidos na comunicação. Nessa fase, a participação do ouvinte é 
de extrema importância, já que se abre a oportunidade para este expor seus conhecimentos e debatê-los. Essa é a razão pela qual sua abordagem é tão relevante na sala de aula, visto que a partir da organização das partes do seminário torna-se mais fácil a organização do texto oral em si, em especial a sua coesão e progressão temática.

No eixo dos fenômenos linguísticos, a progressão temática trata-se de um dos procedimentos que busca estabelecer relações entre as sequências textuais para que o texto, oral ou escrito, ganhe progressão e se constitua em uma sequência textual coesa. Essas relações ocorrem tanto no campo semântico como no pragmático e se caracteriza, de acordo com Koch e Elias (2017),

Conteúdos da oralidade

A relação entre tema e rema contribui para que, no caso do texto oral, especificamente, o falante organize seu discurso e mantenha a construção dos parágrafos sem que se perca o fio da meada, ou seja, a ideia central, como ocorre no excerto abaixo, transcrição do vídeo de aula, exposição dos alunos no seminário escolar, em nossa pesquisa:

\begin{abstract}
ALUNO 1D: (...) É:: sabemos que o ECA é o estatuto da criança e do adolescente, mas...o que: quer: dizer: isso? O:ECA É: cons-titu-í-do pela lei( ) oito sessenta e nove:: do dia treze:: de: julho: de mil novecentos e noventa...Eleé:: () que regula... regulamenta o direito da criança e do adolescente. Tudo o que acontecer com a criança ou o adolescente: pode incluí-la... ${ }^{3}$
\end{abstract}

Nesse trecho, temos a progressão com tema constante, em que o mesmo tema, no caso ECA, é retomado pelo rema ECA e pelo pronome Ele (o estatuto). A partir dos remas o falante consegue expor informações a respeito do tema e é essa estratégia que ajuda o encadeamen-

3 Exemplos retirados das produções orais dos alunos envolvidos na pesquisa de mestrado de um dos autores deste trabalho. 


\section{Cinara Sousa}

da Silva

Adelino

Pereira dos

Santos

to das ideias e introdução de novas informações. Segundo as autoras, a progressão temática pode ocorrer com temas variados, quando na construção textual “de um 'hipertema' derivam-se temas parciais, ou seja, quando um tema se divide em vários outros" (KOCH, ELIAS, 2017, p. 106). Além dessas, ainda é possível ao falante estabelecer a progressão do seu texto por meio da subdivisão do rema, quando ocorre a divisão de um rema em vários outros; ou pela progressão linear, quando um rema passa a ser tema no enunciado seguinte. Caso o produtor do texto, oral ou escrito, utilize uma sucessão de novos temas, então a progressão se caracteriza como progressão com salto temático.

Apesar dessas especificações apresentadas por Koch e Elias (2017), em nossa pesquisa de mestrado, com a aplicação do projeto de intervenção pedagógica sobre o gênero discurso seminário na aula de Língua Portuguesa, o trabalho centrou-se no estudo do tema e rema, da progressão linear, da progressão com tema constante e com temas variados. Como o seminário foi realizado em grupo, tratamos da continuidade tópica, como parte do conteúdo. De acordo com Koch e Elias (2017, p. 111), "podemos dividir um texto em fragmentos recobertos por um mesmo tópico, porém, cada conjunto desses fragmentos irá constituir uma unidade de nível mais alto." Isso significa que para dar continuidade ao texto, no caso o falante, pode utilizar-se de vários segmentos tópicos, os quais formam um subtópico e esses vários subtópicos formam um quadro tópico, podendo ainda formar um supertópico, como exemplificado na figura a seguir:

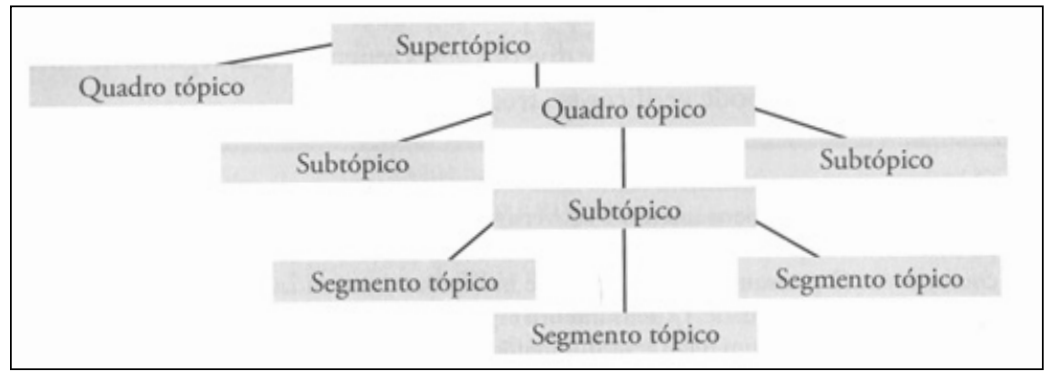

Figura 2 - Representação esquemática da continuidade tópica FONTE: KOCH, ELIAS (2017, p. 112)

$\mathrm{Na}$ figura 2, há uma breve ilustração de como ocorre a continuidade tópica e podemos identificar essa relação intrínseca entre os subtópicos e seus segmentos na compreensão do tópico discursivo, do tema 
geral. Para assegurar a articulação das diferentes partes temáticas o expositor faz uso de conectivos e expressões que também ajudam na organização da sequência tópica e na coesão temática: "agora eu vou falar sobre o perfil dos agressores", "Para concluir... vou falar como combater o bullying...”. Esses elementos linguísticos são fundamentais para que o expositor faça a sinalização do texto, orientando o público durante a exposição: “...o que: quer: dizer: isso?”; “Agora vamos fazer uma pequena demonstração da violência contra a criança".

Quanto à exemplificação, refere-se a uma estratégia linguística, utilizada pelo produtor do texto, com a finalidade de retomar uma ideia anterior e reforçá-la por meio de exemplos que ilustrem o que fora exposto. Essa estratégia é utilizada em diversas tipologias e gêneros discursivos, mas aqui reforçamos sua relevância apenas na exposição Conteúdos da oralidade oral, objeto de análise nesta pesquisa. Segundo Dolz e Shneuwly (2011, p. 190), os exemplos usados em um discurso podem ser explicativos ou ilustrativos e servem para ilustrar, esclarecer ou legitimar a fala do expositor, além de servir como meio de fortalecer a relevância do assunto em pauta e para atrair a atenção do ouvinte.

Outra estratégia discursiva é a retomada e reformulação de falas, que ocorrem quando o expositor retoma seu discurso a fim de reorganizar sua fala e/ou reformular as ideias expostas; atitude que ajuda na sintetização e na mútua compreensão dos interlocutores. Elas podem ocorrer em paráfrases ou como forma de definição: “... como tá dizendo aqui: é:: repetidos... esse repetido quer dizer como se fosse é:: quando exagera nos apelidos..."; “o que é bullying?... "o bullying corresponde a prática de: atos de violência física; ou psicológica...”. Enfim, além desses conteúdos elencados, também relacionados à dimensão linguística, outros fatores são relevantes para a comunicação face a face, a exemplo da linguagem não-verbal.

Em relação aos fenômenos paralinguísticos e cinésicos, considera-se que para Bakhtin (2016) a enunciação é produto da interação social, sendo determinada pelo contexto, imediato ou outro mais amplo. Por isso, além dos aspectos verbais, o homem ao utilizar a linguagem também se vale de elementos fora da língua, os quais se caracterizam como extraverbais. Dessa forma, a parte social do enunciado é que abrange os aspectos extraverbais da língua. $O$ autor afirma que "a língua passa a integrar a vida através dos enunciados concretos (que a realizam); é igualmente através de enunciados concretos que a vida 


\section{Cinara Sousa da Silva \\ Adelino \\ Pereira dos \\ Santos tar associada a algo bem mais amplo que não possa ser reduzida a con- teúdos para o ensino. No entanto, ao pensar no extralinguístico, exis- tem aspectos que precisam ser respeitados pelo falante na produção do texto oral e que se adequem às diversas situações de comunicação e interação sociais. Como também enfatizam Dolz e Schneuwly, \\ A comunicação oral não se esgota somente na utilização de meios linguísticos ou prosódicos; vai utilizar também signos de sistemas semióticos não linguísticos, desde que codificados, isto é, convencionalmente reconhecidos como significantes ou sinais de uma atitude. É assim que mímicas faciais, posturas, olhares, a gestualidade do corpo ao longo da interação comuni- cativa vêm confirmar ou invalidar a codificação linguística e/ou prosódica e mesmo, às vezes, substituí-la (DOLZ; SCHNEUWLY, 2011, p. 134).}

entra na língua" (BAKHTIN, 2016, p. 16,17). É devido a essa relação entre língua e sociedade que se torna indispensável abordar os elementos não-linguísticos no ensino, por compreender sua influência na produção da enunciação.

A parte pragmática da língua, reconhecida por Bakhtin, pode es-

A forma como o texto oral é produzido no seminário, por exemplo, em tempo real e na interação face a face, estimula alterações na maneira como o código é pronunciado e em sua significação. 0 tom, durante a exposição, "tem por função valorizar determinadas palavras, precisando-as melhor, indicar como devemos recebê-las do expositor e revelar toda uma gama de sentimentos deste em referência ao que nos diz" (CAMARA JR., 2003, p. 20). Bakhtin vai além, ao descrever a entonação expressiva como traço constitutivo do enunciado: "um dos meios de expressão da relação emocionalmente valorativa do falante com o objeto da sua fala é a entonação expressiva que soa nitidamente na execução oral" (BAKHTIN, 2003, p. 290). Sendo assim, a prosódia, a área que estuda a entonação, o ritmo, o timbre, a articulação da voz e outros aspectos paralinguísticos, precisa ser valorizada no ensino do gênero, a fim de evidenciar essa relação do dito com o não-dito.

A linguagem corporal, por exemplo, que se constitui em um aspecto cinésico por sua relação intrínseca com a palavra, é um dos conteúdos pouco explorados na sala de aula, mas que influencia principal- 
mente na interação entre os interlocutores. 0 corpo transmite diversas mensagens positivas e/ou negativas durante a comunicação. $O$ falante, principalmente aquele que pratica gêneros de instância pública, em situações formais, deve estar atento a essas informações. Por isso que é viável construir etapas de estudos voltados especificamente para a análise de aspectos como a organização da gestualidade e as expressões fisionômicas, já que "o corpo humano em seu conjunto é capaz de uma linguagem significativa, que serve de complemento ao ato de falar" (CAMARA JR., 2003, p. 20). Em se tratando do ensino desses conteúdos extraverbais, vale destacar o que afirma Travaglia (2013),

Conteúdos da oralidade

Sendo o seminário um gênero formal, cabe ao falante usufruir desses recursos paralinguísticos e cinésicos e usá-los conscientemente, direcionando-os à intencionalidade discursiva. Para reforçar essa característica formal do gênero seminário, torna-se indispensável o cuidado com os protocolos linguageiros, para a polidez na fala e evitar o uso de gírias.

\section{Considerações finais}

Oralidade na sala de aula é um assunto que tem ganhado cada vez mais espaço nos debates relacionados ao ensino de Língua Portuguesa. Mesmo que lentamente, é possível verificar iniciativas em busca do fortalecimento de ações pedagógicas que tratem os gêneros orais como práticas sociodiscursivas e promovam diversas situações de uso da língua. Por muito tempo os gêneros orais ocuparam um lugar secundário no processo de ensino-aprendizagem, provavelmente devido ao equívoco em atribuírem à escrita um status superior ao da fala, e essa é uma das razões que nos impulsionou a elaborar uma proposta em que a oralidade se constitua em um dos eixos a serem explorados de forma sistemática na sala de aula. 


\section{Cinara Sousa \\ da Silva \\ Adelino \\ Pereira dos \\ Santos os PCN (BRASIL, 1997/1998) vêm exigindo do professor um trato maior com os gêneros discursivos orais e escritos, principalmente nas aulas de Língua Portuguesa. Mais recentemente, a Base Nacional Comum Cur- ricular (BRASIL, 2017) estabeleceu a oralidade como um dos eixos que configuram as práticas de uso da língua, enfatizando a necessidade de propostas em que os gêneros sejam trabalhados em situações formais e informais da língua. Como se verifica na declaração a seguir:}

É no cotidiano escolar que conseguimos detectar os reais problemas relacionados ao ensino da língua, que ainda perduram e dificultam o agir do professor, assim como o desenvolvimento do aluno. Um desses problemas, já mencionado, está relacionado ao pouco espaço da oralidade na sala de aula, apesar de que há anos os documentos oficiais como

\footnotetext{
O Eixo da Oralidade compreende as práticas de linguagem que ocorrem em situação oral com ou sem contato face a face, como aula dialogada, webconferência, mensagem gravada, spot de campanha, jingle, seminário, debate, programa de rádio, entrevista, declamação de poemas (com ou sem efeitos sonoros), peça teatral, apresentação de cantigas e canções, playlist comentada de músicas, vlog de game, contação de histórias, diferentes tipos de podcasts e vídeos, dentre outras. Envolve também a oralização de textos em situações socialmente significativas e interações e discussões envolvendo temáticas e outras dimensões linguísticas do trabalho nos diferentes campos de atuação (BRASIL, 2017, p 76-77).
}

O papel da escola como instituição principal na propagação do conhecimento é incluir os gêneros orais, não só do cotidiano do aluno, mas da esfera pública como objeto de ensino, visto que estes possuem regularidades que o tornam de difícil construção. Com isso, as propostas anteriores, organizadas nos PCN (BRASIL, 1997/1998), foram reformuladas no intuito de definir as bases para o fortalecimento do ensino da Língua Portuguesa e da criação de ambientes que estimulem o uso da língua tanto na modalidade escrita como na oral, em suas diversas formas e graus de formalidade.

Apesar dessas orientações nos documentos referenciais, o que muitas vezes vemos persistindo em muitas aulas de Língua Portuguesa é o uso da língua restrito à modalidade escrita, com intenções voltadas para a interpretação de textos e estudos gramaticais; ou ainda 
propostas de atividades de expressão oral que não abarcam o estudo das características dos gêneros em sua totalidade. Não que o professor não reconheça a importância desse trabalho com os gêneros orais, mas por serem diversos os empecilhos que, de certa forma, contribuem para que a oralidade seja posta de lado nas atividades com a língua. Podemos citar a dificuldade que temos em compreender como esses gêneros se caracterizam; o que deles ensinar, como ensiná-los e, principalmente, como utilizá-los para avaliação do desempenho do aluno.

Em consequência disso, lidamos com alunos que ainda apresentam dificuldades nas práticas comunicativas da esfera pública e em situações mais formais. Assim, esperamos que trabalhos como este possam ser incentivadores de mudanças de atitude e quiçá impulsionem tanto outros estudos quanto novas práticas pedagógicas.

Conteúdos da oralidade

\section{REFERÊNCIAS}

BAKHTIN, M. Estética da criação verbal. 4 ed. São Paulo: Martins Fontes, 2003.

BAKHTIN, M (VOLOCHÍNOV). Marxismo e filosofia da linguagem: problemas fundamentais do método sociológico da linguagem. 12 ed. São Paulo: Hucitec, 2006.

BAKHTIN, M. Os gêneros do discurso. São Paulo: Editora 34, 2016.

BRASIL. Base Nacional Comum Curricular: Educação é a base. MEC, versão de 20 de dezembro de 2017.

BRASIL. Parâmetros Curriculares Nacionais: Língua Portuguesa. Brasília: MEC/SEF, 1997/1998.

BAUMGÄRTNER, C. T. Grupo de estudos de língua portuguesa GELP: uma experiência de formação continuada de professores com focos em gêneros orais e ensino. In: BUENO, L.; COSTA-HÜBES, T. C. (Org.). Gêneros orais no ensino. Campinas: Mercado de Letras, 2015, p. 91-115. 
CAMARA JR., J. M. Manual de expressão oral e escrita. 22 ed. Petrópolis: Vozes, 2003.

CAVALCANTE, M. C. B.; MELO, C. T. V. Gêneros orais na escola. In: SANTOS, C. F.; MENDONÇA, M.; CAVALCANTE, M. C. B. Diversidade

Cinara Sousa

da Silva

Adelino

Pereira dos

Santos textual: os gêneros na sala de aula. Versão digital. Belo Horizonte: Autêntica, 2007, p. 89-102.

COSTA-MACIEL, D. A. G. Oralidade e ensino: saberes necessários à prática docente. Recife: EDUPE, 2014.

DOLZ, J.; NOVERRAZ, M.; SCHNEUWLY, B. Sequências didáticas para o oral e a escrita: apresentação de um procedimento. In: SCHNEUWLY, B.; DOLZ, J. Gêneros orais e escritos na escola. 3 ed. São Paulo: Mercado de letras, 2011a, p. 81-108.

DOLZ, J.; SCHNEUWLY, B. O oral como texto: como construir um objeto de ensino. In: SCHNEUWLY, B.; DOLZ, J. Gêneros orais e escritos na escola. 3 ed. São Paulo: Mercado de letras, 2011b, p. 125-155.

DOLZ, J.; SCHNEUWLY, B.; DE PIETRO, J.; ZAHNA, G. A exposição oral. In: SCHNEUWLY, B.; DOLZ, J. Gêneros orais e escritos na escola. 3 ed. São Paulo: Mercado de letras, 2011c, p. 183-211.

; GAGNON, R. O gênero de texto, uma ferramenta didática para desenvolver a linguagem oral e escrita. In: BUENO, L.; COSTA-HÜBES, T. C. (Org.). Gêneros orais no ensino. Campinas: Mercado de Letras, 2015, p. 23-56.

FONSECA, J. Z. B. O processo de didatização dos gêneros discursivos em práticas de ensino de Língua Portuguesa: um diálogo entre a aula e o livro didático. Jundiaí: Paco, 2014.

KOCH, I. V., ELIAS, V. M. Escrever e argumentar. São Paulo: Contexto, 2017.

LEAL, T. F.; GOIS, S. (Org.). A oralidade na escola: a investigação do trabalho docente como foco de reflexão. Belo Horizonte: Autêntica, 2012. 
MARCUSCHI, L. A. Produção textual, análise de gêneros e compreensão. São Paulo: Parábola, 2008.

SILVA, Cinara Sousa da. Conteúdos da oralidade: uma proposta de intervenção pedagógica com o gênero discursivo seminário escolar. 2019. 223f. Dissertação (Mestrado Profissional em Letras) - Departamento de Ciências Humanas do Campus V da Universidade do Estado da Bahia, Santo Antônio de Jesus, 2019.

TRAVAGLIA, L. C. Gêneros orais: conceituação e caracterização. Conteúdos da Anais do SILEL. V. 3, n 1, Uberlândia: EDUFU, 2013. oralidade 
